\title{
Improvement of the nutritional quality of a traditional dish: from a field survey to the optimization of the preparation in the laboratory Sylvie Avallone, ${ }^{1,2^{*}}$, Philippe Bohuon ${ }^{1}$, Youna Hemeri ${ }^{2}$ and Serge Treche ${ }^{2}$
}

\section{Introduction}

The iron deficiency is widespread in most developing countries particularly during the period of complementary feeding of infants and young children. Indeed, sahelian diets are poor in bioavailable micronutrients because they are mainly composed of plant foods (1). The nutritional interest of dishes depends on their micronutrient contents as well as on the frequency of their consumption by the target population and on the quantity ingested per meal. To identify the nutritionally useful dishes of the local diet, the best way is to do a food consumption survey and to estimate their contribution to Recommended Nutrient Intake (RNI) (2). The chemical composition of raw and processed materials is then needed. However, in subsaharian Africa, the micronutrient contents of traditional foods are still not well known as well as the unit operations used to process ingredients. Such data would be of great use to elaborate nutritional interventions. The purpose of the present study was $(i)$ to estimate the contribution of dishes to fulfilling iron RNI in a sahelian area, (ii) to obtain the recipe of the dried okra sauce and (iii) to optimize the content in in vitro digestible iron.

\section{Material and methods}

The survey took place in Ouaregou village located $180 \mathrm{~km}$ to the south of Ouagadougou (Burkina Faso). A 24-h dietary recall was conducted from april to june 2003. It allowed us to collect information on all types of food given to 100 children of 12-23 and 24-59 months-oldchildren, the previous day. Intakes were calculated using micronutrient contents of food $(3,4)$. The dishes were compared using 2 indices of nutritional quality corresponding to their $(i)$ contribution to the child's RNI per meal and (ii) contribution to the child's RNI per day (5).

The recipe of dried okra sauce, main potential source of iron, was written down during home visits of 6 different women. The types and quantities of ingredients, the temperature profiles and the chronology of the unit operations used for processing ingredients were noted. Ingredients were purchased at the market of Ouagadougou and stored at $4^{\circ} \mathrm{C}$. A Doehlert uniform shell design (6) was used to determine the effects of main command variables of dried okra sauce elaboration (in our laboratory) on in vitro digestibility of iron (DIV in.\%) and content in digestible iron (CDI, in $\mathrm{mg} / 100 \mathrm{~g}$ dry matter). The five factors were: $\mathrm{X}_{1}$ as cooking duration in min, $X_{2}$ as dried okra quantity in $g, X_{3}$ as dried fish quantity in $g, X_{4}$ as soumbala quantity in $\mathrm{g}, \mathrm{X}_{5}$ as ash wood extract quantity in $\mathrm{g}$.

\section{Results and discussion}

A total of 29 different dish components were identified. The most frequent starchy dish components were millet-based-tô and rice associated with 3 types of sauces (dried okra, groundnut or red sorrel leaves). Ingested quantities ranged from 89.9 to $183.6 \mathrm{~g} / \mathrm{meal}$ for starchy dish components (rice, millet-based-tô) and from 50.0 to $98.2 \mathrm{~g} / \mathrm{meal}$ for sauces (dried okra sauce, red sorrel leaf sauce). Dried okra sauce was the sauce which mainly contributed to iron intakes of the children. Its recipe was simple: 10 ingredients are boiled in water during 20 $\min$ (Figure 1). 


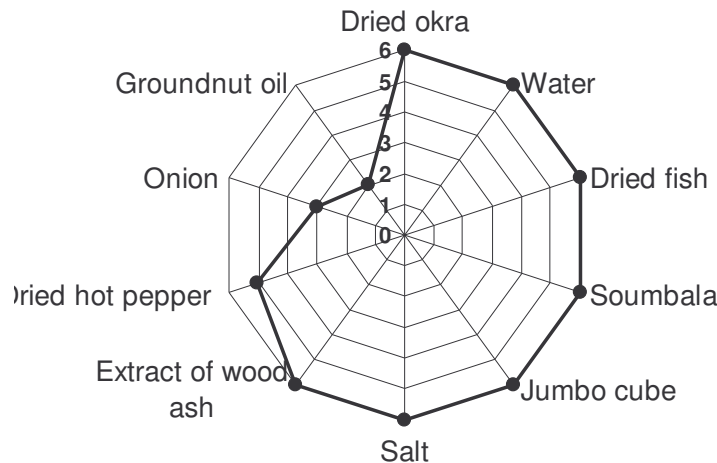

Figure 1. Frequency of ingredients in the dried okra sauce.

In total, 33 sauces were prepared. The CDI model described experimental results with $\mathrm{R}^{2}>0.86$ and, in the middle of the experimental design, CDI was $0.74 \mathrm{mg} / 100 \mathrm{~g}$ and DIV value was low $(\sim 3,1 \%)$. Only linear effects are presented here:

$$
C D I=0.74+0.032 X_{1}-0.174^{* * *} X_{2}-0.151^{* * *} X_{3}-0.055 X_{4}+0.154 X_{5}
$$

with *** coefficient significant at $\mathrm{P}<1 \%$. The duration of cooking had no influence on in vitro iron digestibility contrary to ingredient quantities (Figure 2). Dried okra and dried fish had a negative linear effect on iron digestibility whereas extract of wood ash greatly enhanced the content of digestible iron in the final product. Optimisation allow to define the ideal recipe, in adequation with the local practice, in which CDI reached $1.66 \mathrm{mg} / 100 \mathrm{~g}$.

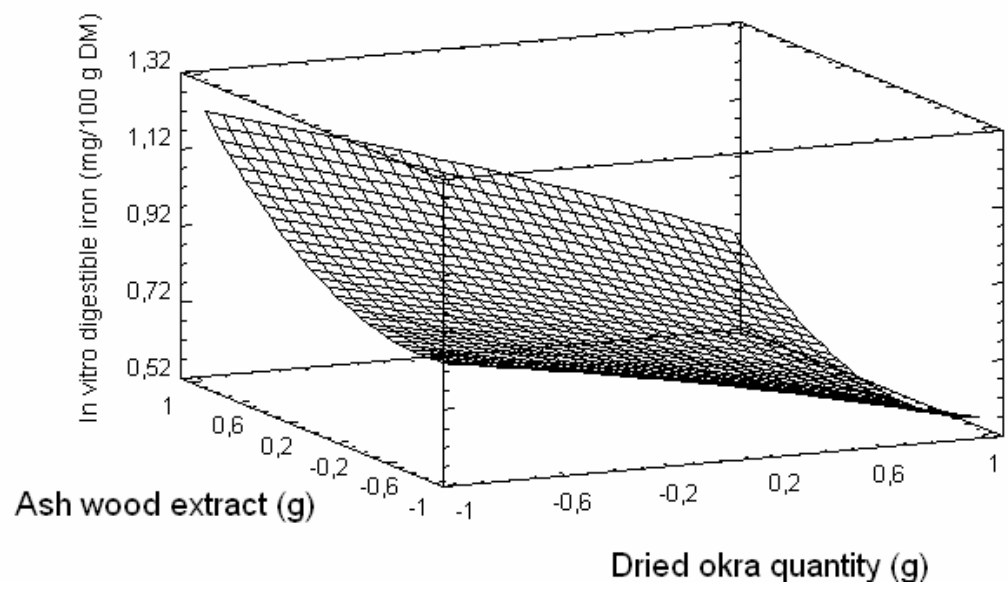

Figure 2. Iron in vitro digestibility according to dried okra and extract of wood ash quantities.

\section{Conclusion}

This survey enabled to identify the determining factors of the iron digestibility in the preparation: cooking had no influence and formulation was the most critical step.

\section{References}

(1) Solomons NW (2000): Plant-based diets are traditional in developing countries: 21st century challenges for better nutrition and health. Asia Pacific J. Clin. Nutr. 9(S), S41-S54.

(2) Ryley J (1984): The nutritional quality of school meals made from convenience foods compared with traditionally prepared dishes. Hum. Nutr. Applied Nutr. 38, 42-49.

(3) Smith GC, Clegg MS, Keen CL, Grivetti LE (1996): Mineral values of selected plant foods common to southern Burkina Faso and to Niamey, Niger, West Africa. Int. J. Food Sci. Nutr. 47, 41-53.

(4) Souci SW, Fachmann W, Kraut H (2000): Food composition and nutrition tables. 6th edn. 1182 p. Stuttgart: Boca Raton CRC Press.

(5) Avallone S, Brault, S, Mouquet C, Treche S. (2006) : Home-processing of the dishes constituting the main sources of micronutrients in the diet of preschool children in rural Burkina Faso. Int J Food Sci Nutr (in press).

(6) Doehlert, DH. Uniform shell design. Appl. Stat. (1970): 19, 231-239. 